\title{
A LA SOMBRA DEL PODER. ADMINISTRACIÓN Y CORRUPCIÓN EN LAS FILIPINAS HISPÁNICAS, EL CASO DE MANUEL ESTACIO VENEGAS
}

ANTONI PICAZO MUNTANER

Universitat de les Illes Balears (Espanha)

\section{RESUMEN}

Una de las consecuencias más inmediatas del poder en las cortes virreinales y en las audiencias fue la delegación de parte de ese mismo poder a personas de confianza. Algunas de ellas, como el caso de Manuel Estacio, forjaron redes a la sombra de la administración para el propio beneficio, gestándose una dinámica corrupta y tiránica.

PALABRAS CLAVE: Filipinas; siglo XVII; poder; corrupción; administración.

\section{ABSTRACT}

One of the most immediate consequences of power in the colonial courts and the audience was part of the delegation of that power to people you trust. Some, like the case of Manuel Estacio, networks forged in the shadow of the administration for their own benefit, brewing a corrupt and tyrannical dynamics.

KEYWORDS: Philippines; XVII century; power; corruption; administration. 


\section{Introducción ${ }^{1}$}

A lo largo del presente artículo analizaremos el comportamiento de aquellos hombres que hábilmente se situaron a la sombra del poder de las élites gobernantes, de los, digamos, validos de gobernadores y capitanes generales ${ }^{2}$, centrándonos, en este caso, en las islas Filipinas - islas supeditadas a un control político y económico en escala, subordinadas a Nueva España pero también a la Corte. Las islas gozaban de un modelo económico que disfrutaba de unas relaciones contractuales con el área AsiaPacífico muy altas, así como con los agentes de las principales compañías que intervinieron en ese mercado, como fueron los ingleses y holandeses ${ }^{3}$, y ello, además, con la participación de agentes de los reinos de la región (India, China, Japón, Cochinchina, Siam, Camboya.... $)^{4}$. Esta misma situación y el nuevo marco contractual generaron una legislación tremendamente coercitiva ${ }^{5}$ para la extensión económica que limitaba las posibilidades de enriquecimiento de la oligarquía mercantil ${ }^{6}$ y aún gubernamental - oligarquía y élites que nunca dejaron de mirar los procesos políticos de la Corte y de asumir como propios los modelos áulicos imperantes en la metrópoli. Efectivamente, en una época de validos, el modelo cortesano ${ }^{7}$ también se instauró en las propias

${ }^{1}$ Este artículo forma parte del proyecto de investigación "Ruta Global: Análisis histórico experimental con base de datos y geovisualización espacio-temporal del comercio marítimo internacional, 1717-1850 (GlobalNet)", financiado dentro del Plan Nacional de I+D+I del Ministerio de Ciencia e Innovación, con número de referencia HAR 2011-27694.

${ }^{2}$ BARROWS, David P. The Governor-General of the Philippines Under Spain and the United. The American Historical Review, Vol. 21, No. 2, pp. 288-311, 1916. El autor explicó en este clásico artículo la peligrosa ubicación de las islas Filipinas, cerca de China y Japón; de las estratégicas islas Molucas, presionadas a la vez por la piratería malaya; y por la irrupción de ingleses y holandeses en la zona. Todo ello implicaba una gran responsabilidad política y militar de los gobernadores y capitanes generales del archipiélago.

${ }_{3}^{3}$ Para el comercio el área del Pacífico, vea: SPRENGARD, Karl A. \& PTAK, Roderich (Ed.). Maritime Asia. Profit, Maximization, Ethics and Trade Structural. Wiesbaden: 1994. Para las factorías holandesas, PARTHESIUS, Robert. Dutch Ships in Tropical Waters. The development of the Dutch East India Company (VOC) Shipping network in Asia, 1595-1660. Amsterdam: University, 2010.

${ }^{4}$ ISHII, Yoneo. The junk trade form Southeast Asia. Singapore: Institute of Southeast Asia, 1998. Vea especialmente el capítulo dedicado al Puerto de Ayutthaya, en Siam - uno de los principales puertos abastecedores de Manila, especialmente activo en la fabricación de navíos para la oligarquía comercial filipina. ISHII, Yoneo et al. From Japan to Arabia: Ayutthaya's Maritime Relations with Asia, White Lotus Co., 1999.

${ }^{5}$ A pesar de todas las restricciones, los habitantes de Manila no se daban por vencidos. En 1604 enviaron una carta al rey demandando que no se cobrara el $10 \%$ sobre la ropa que se enviaba a Nueva España (Archivo General de Indias -AGI. Filipinas, 339L-2, f. 287v). También, en AGI, Filipinas 340 L5, f. 36-40, "Petición de informe para abrir comercio con Perú, 14 de febrero de 1640 ". En este caso fueron las autoridades virreinales que la formularon - si bien su argumento fue "... para reabrir el comercio de Perú con Nueva España y reparar los daños que sufren las Filipinas".

${ }^{6}$ Una de las mejores obras que clarifican de una forma muy notable la dinámica de la vida municipal en Manila es la de ALVA, Inmaculada. La vida municipal en Manila, siglos XVI-XVII. Córdoba: Universidad, 1997.

7 LENSKI, G.. Poder y privilegio: teoría de la estratificación social. Piados: 1993 y WEBER, Max. Sociología del Poder: los tipos de dominación. Madrid: Alianza, 2007 investigaron en su día las distintas estrategias diseñadas para alcanzar el poder, consolidarlo, ampliarlo y conservarlo. 
cortes virreinales y, por extensión, a las audiencias y zonas más remotas, como fue el archipiélago filipino.

La mayoría de los gobernadores y capitanes generales de las Filipinas durante todo el siglo XVII, un siglo de esplendor pero también de crisis, de cambio, de mutación y ampliación comercial, pasaron por grandes procesos judiciales. Algunos de ellos terminaron en prisión, otros murieron, sufrieron golpes de fuerza por su intervención en el comercio, conocieron conjuras con envenenamiento incluido, participaron directamente del contrabando... En algunas ocasiones, los golpes de mano trajeron un cambio en la estructura de poder y el mismo fue asumido, en este caso, no por la élite política, sino por la económica, la que gozaba de unos grandes privilegios contractuales. Algunos de aquellos gobernantes tuvieron una gran personalidad, y su responsabilidad directa en los asuntos políticos, económicos y religiosos fue tremendamente original, provocando, con esa intervención, choques con la oligarquía local. Otros, en cambio, merced a su edad avanzada y a los problemas intrínsecos del poder y de su gestión cotidiana lo dejaron en manos de individuos de confianza, de validos, que bajo su cobertura, diseñaron redes para el beneficio propio, como fue el caso que nos ocupa, las actividades e implementaciones ejecutadas a la sombra del poder por Manuel Estacio Venegas. Estudiaremos el comportamiento y la red forjada por Manuel Estacio Venegas, el último gran valido de los gobernadores de Filipinas, que llegó a detentar unas atribuciones únicas, con un modus operandi absoluto y tiránico mientras tuvo el apoyo incondicional de Fajardo. Personaje que fue escalando posiciones en la administración, creando una verdadera red clientelar que estuvo dedicada, básicamente, a acumular prebendas, mercedes y riquezas, en su mayor parte, fruto del fraude. Pero no fue ni la actitud política, ni la religiosa lo que aceleró y precipitó su caída, sino su intervención en el contrato, el constante acaparamiento de productos y mercados que dinamitaban los intereses económicos de los grandes comerciantes y de las grandes redes novohispanas afincadas en Manila.

En definitiva, el estudio de las redes que dominaron la vida en la Manila del siglo XVII, a través de los análisis de las actuaciones de sus gobernadores, nos introducirá en los oscuros callejones que se formaron a la sombra misma del poder y de las imbricaciones que se gestaron más allá de los simples límites geográficos del archipiélago.

\section{El valido}

Manuel Estacio Venegas, maestre de campo y mano derecha de Diego Fajardo, gobernador y capitán general de las islas Filipinas, tuvo una vida, según sus propios méritos ${ }^{8}$ presentados ante la Corte, bastante ajetreada,

Ambos autores también penetraron en la gran importancia que el prestigio tenía en todos y cada uno de los estratos de la sociedad del Antiguo Régimen.

${ }^{8}$ AGI, Indiferente General, 113 N 118. 
sirviendo como soldado a lo largo de más de treinta y dos años. Como era normal en la época, los méritos personales que exhibió fueron una autobiografía extremadamente exagerada, cuando no cayó en mentiras flagrantes. Destacó su participación en los diferentes combates de 1615 en la Armada del Atlántico a bordo del galeón San Miguel, comandado por el general de la flota Luis Fajardo; más tarde luchó contra los holandeses en el cabo de San Vicente - batalla en la que fue herido, aunque siguió peleando hasta el último momento. Dichos hechos fueron puestos en duda y desmentidos posteriormente por el fiscal de la Audiencia de Manila, Francisco de Samaniego ${ }^{9}$, que le acusó de infidelidad para con el monarca, argumentando que todas esas informaciones eran un verdadero fraude. Seguidamente, según su propia versión, pasó al Mediterráneo, en las galeras capitaneadas por Francisco Maza, enfrentándose a los turcos en Fuengirola y en diversas plazas del norte de África. A los pocos años retornó a la flota del Atlántico, pasando ulteriormente al Caribe, área en donde volvió a enfrentarse a los holandeses, concretamente en la zona de Campeche. En 1625 pasó a Filipinas participando en la expedición enviada al presidio de Terrenate. Posteriormente, combatió a las órdenes del gobernador Sebastián Hurtado de Corcuera en la defensa de Manila durante el levantamiento que en 1639 protagonizaron los chinos del Parián.

Entre las múltiples causas que precipitaron el levantamiento chino del Parián, hallamos la intención de Corcuera de obligarles a cultivar arroz. En una carta de 1638 ya se advertía del peligro que representaba la gran llegada masiva de chinos y su establecimiento extramuros de la ciudad, donde, al parecer, residían más de cinco mil personas. La cuestión que se complicaba enormemente por la autorización que habían recibido unos años antes para poder dispersarse por los alrededores de Manila, pudiendo vivir fuera de la zona denominada 'Parián'10. No obstante, tras la aparición de diversas prohibiciones y reglamentaciones, como la del juego, la tensión se incrementó por momentos. Tanto era así que el mismo Corcuera envió una carta a las autoridades de la ciudad para que evitaran, en lo posible, mostrarse demasiado arrogantes cuando visitasen el Parián ${ }^{11}$.

Ya asentado definitivamente en Manila, Manuel Estacio contrajo matrimonio con María de Perona, la hija del general Fernando López de Perona, uno de los comisionados enviados a México en 1629 para gestionar los intereses comerciales de Filipinas y de la gran élite mercantil del momento. Mediante esta unión, pudo forjar una estrecha alianza con esa familia, extendiéndose además sus contactos a la Nueva España. Como consecuencia de sus méritos, y tras su escalada hacia el poder, se le otorgaron una serie de encomiendas $^{12}$. Entre ellas, las de Bonbon, Candon, Cavisilán, Lipa, Sala,

\footnotetext{
${ }^{9}$ AGI, Filipinas, 273, N2. Provisión de Francisco Samaniego Tuesta como fiscal y oidor de la Audiencia de Manila, 1651.

${ }^{10}$ AGI, Filipinas, 330 L4, fol. 52 y ss.

${ }^{11}$ AGI, Filipinas, $28 \mathrm{~N} 1$ Carta del secretario del gobernador al alcalde ordinario, 1638.

12 HIDALGO, Patricio. Encomienda, tributo y trabajo en Filipinas, 1570-1608. Madrid: Polifemo, 1995 y ÁLVAREZ, L. A. Sobre la naturaleza de la fiscalidad imperial en las islas Filipinas: 15651804: lugares comunes y evidencias empíricas. In: SÁNCHEZ, E; JÁUREGUI, L. e IBARRA, A.
} 
Tanauan, Bauan o Mindoro, que le proporcionaron rentas en tributos por un valor superior a los 1.600 pesos anuales, aunque también tuvo que invertir para la compra de voluntades para obtener esas misma rentas. Además de la participación de Estacio en los acontecimientos militares antes descritos, facilitó varios préstamos a la siempre necesitada caja real de Manila. En virtud de todo ello y como premio a sus esfuerzos se le otorgó el título de canciller de la Audiencia ${ }^{13}$ de Filipinas, lo cual fue el inicio de un verdadero asalto al poder.

Esa escalada hacia el poder condujo Estacio a la creación de una intrincada red de colaboradores en diversas zonas geográficas que abarcaban puertos y zonas nucleares de Asia, América y, lógicamente, España. La misión principal de esta red fue el comercio activo al margen de las vías legales y la acumulación de mercedes y capital. Esa red posteriormente colisionó con el recién nombrado fiscal Francisco de Samaniego y precipitó su caída y la apertura de numerosos procesos de residencia, tanto contra soldados como contra oficiales reales e incluso contra almirantes y generales. El juicio afectó a todas las estructuras del poder del archipiélago, llegando hasta el funcionariado de la Casa de Contratación y terminó con la condena a muerte por cuchillo de Manuel Estacio. Esta situación, que también salpicaba a miembros del Consejo de Indias, tuvo que salvarse rápidamente antes que el número de procesados aumentase y el escándalo se centrase no en Filipinas, sino en Sevilla y Madrid. Se solucionó ascendiendo a Samaniego, con lo cual se le apartaba de su cargo de fiscal. Con el nuevo fiscal, la causa se concluyó por la vía de urgencia y a los pocos años el mismo gobernador indultaba a un Estacio viejo y derrotado de la muerte que le esperaba, archivándose el caso definitivamente.

Esta situación de ilegalidad manifiesta y caos organizado en que estaban inmersas las islas provenía del hecho que Fajardo era un hombre muy viejo, con muchos achaques que le impedían ejercer el cargo en la forma que se esperaba. Fajardo, ante esa situación personal, había delegado, cada vez más, a Estacio como su mano derecha y 'perfecto' valido. Con esta coyuntura tan favorable, Estacio inició sus actuaciones para incrementar su poder $y$, con ello, sus beneficios. Entre estas actuaciones, hallamos la acumulación de un gran número de encomiendas; el acaparamiento de productos de las almonedas públicas y de los de más alta calidad que llegaban con los juncos chinos o las naves indias y japonesas; el comercio cada vez más activo en el galeón desplazando a otros comerciantes, con el beneplácito del gobernador, según el fiscal Samaniego; el control absoluto de todas las mercancías y capitales que llegaban de México y las presiones a notables comerciantes ${ }^{14}$; el

(Coords.). Finanzas y políticas en el mundo iberoamericano. Del Antiguo Régimen a las naciones independientes. México: UNAM, 2001, pp. 77-114.

${ }^{13}$ BURKHOLDER, Mark; CHANDLER, D. S. De la impotencia a la autoridad: la corona española y las audiencias en América, 1687-1808. México: FCE, 1984. CUNNINGHAM, Charles. The Audiencia in the Spanish Colonies, N. Y.: Gordian Press, 1971.

${ }^{14}$ CASTAÑEDA, Carmen (comp.). Círculos de poder en la Nueva España. México: CIESAS, 1998. 
destierro y/o asesinato de las personas críticas con el nuevo valido e, incluso, la ocultación y/o destrucción de cédulas y órdenes reales que pudieran lesionar sus intereses o menoscabar, en parte o en todo, su poder.

Otro ejemplo del deterioro de la legalidad lo demuestran las actuaciones que realizaron las autoridades de Filipinas en oposición a la normativa emitida por la metrópoli. Efectivamente, en 1645 el gobernador de Filipinas Diego Fajardo admitió en el puerto de Manila, a instancias del propio Estacio, a un patache inglés que procedía de la factoría de Surate ${ }^{15}$, excusándose que tal comercio era vital, pues proporcionaron a la isla los bastimentos necesarios para su defensa, como era "...salitre, fierro, bronce para fundir artillería..."16. Consecuente, con estas necesidades remitió a la Corte una petición de Eduard Pearce y Thomas Bretton ${ }^{17}$ en que se reclamaba el permiso para mantener un comercio estable con las factorías inglesas de la India $^{18}$. Al mismo tiempo, el embajador español en Inglaterra, Alonso de Cárdenas, remitía la petición oficial de la East India Company a la Corte hispana ${ }^{19}$, documento analizado por el Consejo de Indias ${ }^{20}$ y también por el consulado de mercaderes de Sevilla, desestimándose tal pretensión ${ }^{21}$.

Manuel Estacio Venegas se caracterizó, durante su mandato a la sombra de Fajardo, no solo por el acaparamiento de mercedes y pequeños y grandes fraudes al fisco real, sino también por ejercer un gobierno tremendamente tiránico, que generó el temor de muchos y el odio de más. A lo largo de todo el proceso iniciado por el fiscal Samaniego, además de Estacio, se encarceló a toda la cúspide de la red forjada por el valido, entre ellos al capitán Andrés de Galves, secretario de gobierno; a su ayudante, Gregorio del Castillo; a Pedro Moreno; al escribano público Juan de Torres y a Lucas Veles. A Estacio se le acusó de una gran relación de delitos, tales como infidelidad al monarca, fraude fiscal, asesinato, robo, etc. y una larga lista de otras prevaricaciones como el de manejar a los alcaldes ordinarios a su capricho, siendo, según el propio Samaniego, un verdadero especialista en "...conseguir la gracia y atraerse la voluntad de la persona que necesitare su favor, procurándole darle gusto, desacreditando a aquellas que no podía atraer." ${ }^{\prime 22}$

Otro de los cargos, tal vez el más interesante, pues evidencia esa lucha de redes por el poder, fue el arresto de la élite misma de la red forjada por Estacio. Entre ellos encontramos a los capitanes Juan Salinas, Fernando

\footnotetext{
${ }^{15}$ AGI. Advertencia sobre admisión de ingleses para comerciar. Filipinas, 330 L4, fols. 191-192, 1646.

${ }^{16}$ AGI. Filipinas, 9-R-1-N-1, fol. 1.

17 AGI. Copia de lo capitulado sobre el comercio con factorías inglesas, 15 de junio de 1645 . Filipinas, 22-R1N1F, fols. 14-75.

18 AGI. Represión a la Audiencia de Manila por el comercio realizado con extranjeros, 1647. Filipinas, 330 L4, fols. 203-204.

${ }_{19}$ AGI. Consulta sobre la propuesta de la Compañía inglesa de la India Oriental, 1647. Filipinas, 2 N73.

${ }^{20}$ AGI. Respuesta al gobernador sobre el comercio con los ingleses, 1649. Filipinas, 330, L4, fols. 237-238.

${ }^{21}$ AGI. Represión a oficiales reales por comercio realizado con extranjeros, 1647. Filipinas, 330, L4, fols. 204-206.

${ }^{22}$ Ibídem, fol. 204 r.
} 
Cordero y Diego de Miralles. Además, el fiscal trató con excesivo rigor a altos funcionarios de la administración, como a Iñigo de Villareal, a Diego Felipe de Morea, a Alonso Centeno, a Blas Polo y al general Cristóbal Romero ${ }^{23}$. Entre las múltiples acusaciones formuladas por el fiscal contra Estacio, figuraba una que nos llama la atención: Estacio Venegas mintió en algunos puntos de sus méritos alegados para obtener determinadas mercedes, entre ellas, la que nunca había estado prestando servicios en la armada del Mar Océano.

Samaniego iba acumulando cargos y pruebas, como la del saqueo de algunos productos embargados a una nave portuguesa, en 1648, o el participar en la compra-venta, tanto para sí mismo, como para sus allegados, de grandes cantidades de mercancías que eran enviadas fraudulentamente a Acapulco ${ }^{24}$. Algunas personas habían intentado denunciar la situación ${ }^{25}$, las cuales, ante el tremendo poder del maestre de campo, fueron desterradas a Terrenate. Algunos de ellos pudieron escapar de ese destierro, como Diego de Hinojosa, de Villavicencio, que embarcó en un barco danés $y$, tras navegar hasta la India y Mozambique, llegó a la Corte donde interpuso una acusación formal contra las actuaciones tiránicas y los múltiples delitos del maestre de campo $^{26}$.

A Estacio Venegas también se le acusó de acaparar todo el comercio que se efectuaba con la costa Malabar, Siam y Camboya, así como de controlar todo el estanco de naipes, de cal y de papel ${ }^{27}$, desviando parte de esas rentas reales a sus propios negocios y hacienda, así como a uno de sus vicios más conocidos y populares: el juego. Efectivamente, fueron muchos los testigos que afirmaron que pagó elevadas deudas de juego, en algunos casos de unos 2.000 pesos, con cargo a la caja real.

Otra de las acusaciones destacables contra Estacio fue que todos los capitanes de champanes que arribaban de las costas chinas debían pagarle un tributo personal, dependiendo de la carga, llegando a convertirse en un impuesto más, que ascendió al pago de dos fardos de lienzo o su correspondiente en metálico de 200 pesos. Esos negocios con los vendedores chinos y los sangleyes del Parián no acababan aquí, pues adquirió algunos inmuebles en esa zona y los arrendaba a mercaderes asiáticos, vendiendo

\footnotetext{
${ }^{23}$ Entre otros muchos servicios prestados, Romero fue castellano y justicia mayor del puerto de Cavite, uno de los puestos clave para el control de las mercancías. Con una dilatada carrera de más de cuarenta y tres años, participó en el abastecimiento de varios presidios, combatiendo en varias ocasiones contra los holandeses en las islas Molucas, o en la isla Hermosa. Como general del galeón, realizó cinco viajes hasta Nueva España.

${ }^{24}$ AGI. Expediente sobre procedimientos contra Francisco Samaniego Tuesta, 1650. Filipinas, 65 N1, fol. 237 r.

${ }^{25}$ AGI. Filipinas, 330 , L.6, f. 17 y ss.

${ }^{26}$ AGI. Petición de Diego de Hinojosa sobre abusos de Manuel Estacio Venegas. Filipinas, 43, N8. Este documento incluyó el testimonio de Juan de la Cueva Morán, escribano público, que confirmaba que Diego de Hinojosa, en marzo de 1646, ya había presentado una petición sobre los abusos de Manuel Estacio Venegas. Junto a ella se halla una carta de Diego Fajardo, de 1648, en la que también confirmó que diferentes personas, entre ellas Cristóbal Galindo, pudieron salir de Filipinas en naves extranjeras huyendo de la represión de Estacio.

${ }^{27}$ GARCÍA, M. Fernanda. La intendencia de Filipinas. Granada: Universidad de Granada, 1983.
} 
licencias para actuar como comerciantes en las islas. También controlaba todos los envíos de trigo, hierro y clavazón que enviaban de China para el abastecimiento de las islas, en lo que acabó siendo un auténtico monopolio. Samaniego igualmente pudo demostrar que en 1646 recibió 100.000 pesos de Nueva España de diferentes personas para sus negocios, dinero este que iba fuera de registro. En 1649 su yerno, el general Lope de Colindres, que estuvo a cargo del galeón, introdujo 80.000 pesos, también fraudulentamente. Posteriormente, en 1652, Samaniego tomó residencia por la pérdida del galeón que venía de Nueva España, 'Nuestra Señora de la Encarnación' a Lope de Colindres.

Pero, sin duda, las acusaciones más graves contra Estacio fueron las de asesinato. Samaniego consideraba que Estacio Venegas había hecho envenenar a los maestres de campo Lorenzo de Olaso, Fernando de Ayala y al general Sebastián López a través de su hombre de confianza Gregorio del Castillo $^{28}$. Dichas acciones provocaron el terror de muchos informantes, llegando a afectar a las testificaciones de ellos, ya que temían seriamente por su vida. Tal era el poder del valido que incluso había modificado las declaraciones en juicios anteriores a su antojo, ocultado cédulas reales hasta el punto de considerarlo "...tan poderoso y vengativo que aun estando preso, le temen..." ${ }^{\prime 29}$. Dada esta situación, fue aislado e quedó incomunicado, bajo pena de vida para todo aquel que rompiera la pretensión de salvaguardar la seguridad de los testigos. Samaniego también pudo acreditar documentalmente algunas actuaciones ilegales realizadas por Estacio, entre ellas el embargo del capital enviado en el galeón Nuestra Señora del Rosario por varios comerciantes novohispanos, suma que ascendía a 101.900 pesos. Esa cantidad era propiedad de los mercaderes más activos de la carrera transpacífica, concretamente de Francisco de Montemayor, Domingo de Mendiona, Mateo Bayón, Baltasar Pereyra, Benito Ximénez, Francisco Martínez, Damián Calvo y Juan Camacho de Peña.

Pero la gran suerte de Samaniego fue el haber registrado los aposentos de Estacio Venegas y haber hallado dos documentos claves para poder mantener sus acusaciones: un libro de contabilidad y un copiador de correspondencia. En el primero de los libros se hallaron transferencias de capital enviado fuera de registro con los datos oportunos: año, consignatario del capital a bordo del galeón, pertenencia y total. Así, en 1645, el capitán Pedro de Urquisu acarreó hasta Manila la cantidad de 30.000 pesos enviados por Martín de Sepúlveda; en 1646 el general del navío San Luis, Fernando López de Perona, trajo 20.000 pesos a Estacio de Tiburcio de Urea ${ }^{30}$.

Ese mismo año, y para hacernos una idea del capital fraudulento manejado por la red, el mismo general anterior también transportó a Filipinas

\footnotetext{
${ }^{28}$ AGI, Filipinas, 56 N1, "Expediente sobre procedimientos..." fol. $414 \mathrm{r}$.

${ }^{29}$ Ibídem, fol. 474 r.

30 Tiburcio de Urea fue miembro del poderoso consulado de comerciantes de México. Vid. HAUSBERGER, Bernd e IBARRA, Antonio. Comercio y poder en América colonial: los consulados de comerciantes, siglos XVII-XIX. México: Iberoamericana, 2003. Sobre la trasgresión de la normativa legal, vid. DEL VALLE PAVÓN, Guillermina. "Los mercaderes de México y la trasgresión de los límites al comercio pacífico en Nueva España, 1550-1620", Revista de Historia Económica, Volumen 23, (2005) , pp 213-240.
} 
la cantidad de 16.000 pesos de Juan Vázquez, 4.000 pesos de Juan de Chalarreta y 14.000 de Andrés del Rosal. Asimismo, Luis Vázquez le despachó 15.000 pesos con el encomendero Martín de Eguiluz. Entre sus pagos también figuraban dádivas a personajes clave de la metrópoli, en este caso, una serie de cajones que contenían diversos regalos enviados al II Conde del Castrillo, García de Avellaneda y Haro, miembro de los Consejos de Estado y Guerra y presidente del Consejo de Indias ${ }^{31}$ y otros tantos, a Francisco Zapata para promover las pretensiones y mercedes demandadas. Para ello, Estacio Venegas tenía una serie de buenos contactos en España. Así, en Madrid estaban José Ferriol ${ }^{32}$ y Juan Bautista Sáenz de Navarrete, que fue secretario del Consejo de Indias, al que remitió diferentes partidas de caudales $y$, en Sevilla, hallamos al doctor Juan Marín de Miejo y al padre Magino. A todos ellos les mandó dinero y también una serie de presentes para comprar voluntades. Entre esos presentes destacaríamos una cadena de oro valorada en unos 300 pesos, 8 libras de almizcle, y seis baúles de marquetería de alta calidad procedentes del Japón. Entre las mercedes que solicitó, previo desembolso de 12.000 pesos, está la de obtener una larga lista de encomiendas que le reportaron unos 1.600 pesos anuales de renta.

En el copiador de correspondencia hallamos notas sugerentes a diversas actividades ilícitas. Entre ellas, una lacónica que expone "A Juan Díaz, maestre de Navío. Se entregue al sargento mayor, Julián de Torres, lo que a mí se me enviase fuera de registro"33; o los movimientos que hizo para ganar la plaza de maestre de campo a través de Sáenz de Navarrete "...Y para la pretensión de la sucesión de la plaza de maestre de campo con el sueldo de entretenimiento della están en Sevilla diez mil pesos que dará la persona que a V.M. avisarán, Juan y Luis Vázquez de Medina, vecinos de México, mis agentes, a quienes escribo lo hagan avisando a V.M... y asimismo va a perdonar mi atrevimiento en el envío que hago a V.M. por mano del capitán Diego Gómez del Castillo de seis salvillas de plata de filigrana, con sus tocantes de lo mismo y de las treinta y tres onzas de almizcle advirtiéndole a V.M. que no ha salido otro mejor de Philipinas, pues lo hize traer del reino de Camboya"134.

Sin embargo, a lo largo del proceso, Samaniego topó de nuevo con un antiguo enemigo, el oidor Ocampo, que tenía que ver el juicio contra Estacio y

\footnotetext{
${ }^{31}$ SCHÄFER, Ernst. El Consejo Real y Supremo de Indias: su historia, organización y labor administrativa hasta la terminación de la casa de Austria. S.L.: 1935.

32 Se le abrió un proceso por haber recibido sumas de Estacio Venegas, Véase AGI, Filipinas, 43, N11 "Oficio de Juan Bautista Sáenz Navarrete a Juan Bautista Berardo dando cuenta de que se ha concedido a José Ferriol la composición del pleito por el que el fiscal le pedía la restitución de 3.000 pesos que recibió de Juan Bautista de Loyola, vecino de Sevilla, para negocios de Manuel Estacio Benegas, residente en Filipinas. Se ha ofrecido a pagar 5.000 reales de plata. Madrid, 10 de enero de 1657".

${ }^{33}$ AGI, Filipinas 56 N1, "Expediente sobre procedimientos..." , fol. $475 \mathrm{r}$.

${ }^{34}$ Ibídem, fol. $1017 \mathrm{v}$.
} 
a quien Samaniego recusó, lo cual condujo a la parálisis procesal ${ }^{35}$. Recusación que, entre otros temas, ponía el acento en las evidentes relaciones de amistad entre Ocampo y Estacio Venegas. Al parecer, este último había realizado un préstamo al primero ${ }^{36}$. No obstante, se declaró no haber lugar ni a dicha recusación ni a todas las demás que había presentado Samaniego contra Ocampo.

Pero Samaniego no pudo concluir la causa ${ }^{37}$, ya que en el último momento fue ascendido a oidor de la Audiencia, muriendo a los pocos años en dicho cargo, al ser sustituido en la fiscalía por Juan de Bolívar y $\mathrm{Cruz}^{38}$. Paralelamente a este ascenso, y ante el temor de la extensión del juicio a la península, las autoridades emitieron un informe sobre algunas actuaciones ilícitas de Samaniego ${ }^{39}$ que hipotecaban el procedimiento.

Esta situación se recondujo con la llegada del nuevo gobernador, Sabiniano Manrique de Lara, pues al haber ascendido a Samaniego y nombrado como fiscal a Juan de Bolívar el proceso de recusación contra Ocampo quedaba anulado, pudiéndose seguir el mismo. No obstante, Ocampo también fue apartado y prosiguió la causa un nuevo oidor, Salvador Gómez de Espinosa $^{40}$. Él empezó las diligencias para hallar los bienes embargados a Estacio Venegas. Dichos bienes nunca aparecieron y las diligencias comenzaron por dar tormento al reo, sin que pudiera averiguarse nada del asunto. A partir de ese momento el juicio se aceleró, se dictó una rápida sentencia de muerte (que posteriormente fue conmutada). Todo ello no impidió que Estacio, gravemente enfermo, falleciese poco tiempo después.

A los pocos años, la viuda de Estacio Venegas interpuso un pleito contra Juan de Bolívar, argumentando que el fiscal se había incautado de 3.000 pesos que le pertenecían. En la sentencia se condenaba a Bolívar a devolverlo, pero tras siete años, el pago aun no se había realizado. Eso motivó

\footnotetext{
${ }^{35}$ AGI, Filipinas, 330 L5. "Respuesta a Samaniego Tuesta sobre asuntos de Justicia". En esta se contiene la Real Cédula a Francisco Samaniego Tuesta, fiscal de la Audiencia de Manila, en respuesta a su carta de 20 de julio de 1652, sobre la detención y embargo de su hacienda a Manuel Estacio Venegas; sobre el oidor Álvaro García de Ocampo, juez asesor de las causas de Manuel Estacio Venegas y lo poco versado que está en práctica y estilo de sustanciar pleitos; sobre la toma de residencia a Lope de Colindres; sobre la posibilidad, recogida en la recopilación, de poder imprimir los pleitos fiscales y sobre las aprobaciones de algunos sujetos de las islas.

${ }^{36}$ AGI, Filipinas, 65-N1, fol. 80 y ss. "Traslado de justificación de Diego Fajardo del préstamo que Manuel Estacio Venegas hizo a Álvaro García de Ocampo. Manila, 2 de mayo de 1654".

37 AGI, Filipinas, 22 R4 N5. "Carta de Francisco Samaniego sobre Estacio Venegas", en esta misiva, junto a la información de la apertura de la causa, solicitó una plaza en cualquiera de las tres audiencias de Nueva España debido a las fuertes presiones que sufría.

${ }^{38}$ Un personaje que representa perfectamente el éxito de los oficiales reales fue abogado de la Audiencia de México, fue alcalde de la casa de la Moneda, comisionado en Yucatán para Bienes de Difuntos, oidor en la Audiencia de Guadalajara, fiscal y oidor en Manila y de mayor solicitó su traslado de nuevo como oidor a la Audiencia de Guadalajara. Vid. AGUIRRE SALVADOR, Rodolfo. Carrera, linaje y patronazgo. Clérigos y juristas en Nueva España, Chile y Perú, siglos XVI-XVIII. México: Plaza y Valdés, 2004.

${ }^{39}$ AGI, Filipinas, 65-N1, fols. 585 y ss. "Carta de la Audiencia de Manila: Sabiniano Manrique de Lara, Juan de Bolívar y Cruz y Salvador Gómez de Espinosa, informando sobre las acusaciones de Diego Fajardo en su carta de 4 de agosto de 1650 contra Francisco Samaniego. Manila, 15 de julio de 1656".

${ }^{40}$ AGI, Filipinas, 285 N1, "Carta de Sabiniano Manrique de Lara sobre materias de justicia".
} 
otra denuncia y, como consecuencia de esta, se abrieron diligencias para averiguar no sólo qué había pasado con dicha cantidad, sino que también se amplió a las actividades comerciales del fiscal ${ }^{41}$.

\section{Conclusiones}

Todas estas circunstancias, la creación de redes de poder visibles (aquellas de carácter legal que buscaban un determinado espacio político, social y económico a través del comercio) o las invisibles (las ilegales, las que perseguían metas de carácter económico a través del contrabando o del comercio prohibido con otros reinos y/o potencias europeas del área AsiaPacífico) venían determinadas por la propia configuración espacial de las islas Filipinas, sus acti y su lejanía.

Las líneas básicas que posibilitaron y consolidaron esta dinámica fueron las siguientes:

En primer lugar, la inmensa distancia de las islas respeto a la metrópoli, al poder central en España, facilitaba el nacimiento de unas redes tremendamente independientes de ese mismo poder central, con unas directrices propias y con unas metas trazadas en virtud de las circunstancias económicas de la zona y los intereses de sus componentes. Además, las débiles conexiones con Nueva España también allanaban el camino a una cierta 'autonomía', con un carácter muy particular, que en muchos casos, y más en los comerciales, chocaba de pleno con los intereses administrativos y/o cortesanos, pero también con la de las élites comerciales afincadas en Sevilla.

En segundo lugar, las circunstancias económicas estaban basadas en las grandes posibilidades que brindaba el comercio internacional en AsiaPacífico, así como los altísimos beneficios netos que reportaba y que en algunos productos alcanzaban el $800 \%$. No obstante, la coerción, la aparición de un corpus legal tremendamente restrictivo para los habitantes de Manila, provocó que los beneficios se buscasen a través de redes ilegales, de redes invisibles. Ello forjó un cambio brusco, sistémico, que perduraría a lo largo de las centurias y que afectaría por igual a toda la élite de Manila, pero que también tendría una extensión 'invisible' con las grandes redes de comerciantes novohispanos que afincaron agentes en el archipiélago $y_{\text {, por }}$ supuesto, con la compra de voluntades del personal de la administración tanto en Manila como en Acapulco - encargado de la vigilancia y persecución del contrato ilegal.

En tercer lugar, la articulación misma del poder entorno al gobernador y capitán general de las Filipinas, en casi todas sus facetas, y la creación de una red a su sombra en demanda de ganancias, de un espacio mercantil que en otras circunstancias no hubieran podido lograr, de la inversión en otros

\footnotetext{
${ }^{41}$ AGI, Filipinas, 21-N-1-R1.
} 
puertos nucleares de Asia (especialmente en Siam y Camboya) provocaron el choque con otras instituciones, con otras redes ubicadas en Filipinas: las religiosas, las del poder local y las de los grandes mercaderes novohispanos.

Finalmente, y a modo de conclusión general, cabe incidir la idea de 'pertenencia' a un sistema. Ciertamente, las Filipinas quedarían rápidamente integradas en un mercado global, a un sistema económico que superaba el propio espacio filipino e incluso metropolitano. Esta inclusión de Filipinas en todo el circuito gestado en esa primera Edad Global imprimió una notable diferencia entre la percepción metropolitana y la insular.

Mientras en la metrópoli aún pervivían viejos dictados mercantilistas, coercitivos, plegados en función del mercado interno, de protección completa a los grandes mercaderes sevillanos, en Filipinas se optó por un pragmatismo que buscaba la eficiencia comercial, la colaboración intersistémica entre los distintos participantes del activo comercio asiático, fuesen ellos europeos (ingleses, holandeses, daneses) o fuesen de los reinos comarcanos (China, Japón, Siam, Camboya, India, Malasia,...). Los agentes conectivos fueron los capitanes de navíos que aportaron los productos al puerto de Cavite. Por ello, las Filipinas participaron de la red mercantil del área Asia-Pacífico y estuvieron supeditadas a las dinámicas y tensiones que iban apareciendo. Eran tensiones globales, pero también regionales y locales que tuvieron la virtud, en algunos casos, de alterar las relaciones contractuales entre las partes.

\section{Sobre o autor}

Antoni Picazo Muntaner é professor doutor da área de Historia Moderna no Departamento de Ciências Históricas e Teoria das Artes na Universitat de les Illes Balears na Espanha. E-mail: a.picazo@uib.es

Artigo recebido em 23 de janeiro de 2014. Aprovado em 15 de junho de 2014. 